\title{
The end of a dogma: the safety of doxycycline use in young children for malaria treatment
}

Tiphaine Gaillard', Sébastien Briolant ${ }^{2,3}$, Marylin Madamet ${ }^{2,3,4}$ and Bruno Pradines 2,3,4*

\begin{abstract}
Anti-malarial drug resistance to chloroquine and sulfadoxine-pyrimethamine has spread from Southeast Asia to Africa. Furthermore, the recent emergence of resistance to artemisinin-based combination therapy (ACT) in Southeast Asia highlights the need to identify new anti-malarial drugs. Doxycycline is recommended for malaria chemoprophylaxis for travel in endemic areas, or in combination with the use of quinine for malaria treatment when ACT is unavailable or when the treatment of severe malaria with artesunate fails. However, doxycycline is not used in young children under 8 years of age due to its contraindication due to the risk of yellow tooth discolouration and dental enamel hypoplasia. Doxycycline was developed after tetracycline and was labelled with the same side-effects as the earlier tetracyclines. However, recent studies report little or no effects of doxycycline on tooth staining or dental enamel hypoplasia in children under 8 years of age. In the United States, the Centers for Disease Control and Prevention have recommended the use of doxycycline for the treatment of acute and chronic $Q$ fever and tick-borne rickettsial diseases in young children. It is time to rehabilitate doxycycline and to recommend it for malaria treatment in children under 8 years of age.
\end{abstract}

Keywords: Antibiotics, Doxycycline, Malaria, Plasmodium falciparum, Anti-malarial drug, Resistance, Prophylaxis, Treatment, Children

\section{Background}

According to the latest World Health Organization (WHO) estimates, nearly half of the world's population lived in malaria endemic areas in 2015 [1]. The burden of malaria predominantly affects sub-Saharan Africa accounting for $90 \%$ of the 212 millions of malaria cases and $90 \%$ of the 429,000 deaths. Most of the cases of malaria in 2015 were in Africa (90\%). Children are especially vulnerable and represented more than $90 \%$ of the malaria cases in Africa. The highest proportion of deaths was averted in Africa (94\%). Of the estimated 6.8 million fewer malaria deaths between 2001 and 2015, about 6.6 million (97\%) were for children aged under 5 years. In 2015, 303,000 malaria deaths (range: 165,000-450,000)

\footnotetext{
${ }^{*}$ Correspondence: bruno.pradines@gmail.com

${ }^{2}$ Unité de Parasitologie et d’Entomologie, Département des Maladies Infectieuses, Institut de Recherche Biomédicale des Armées, HIA Laveran, Boulevard Laveran, 13013 Marseille, France

Full list of author information is available at the end of the article
}

were estimated to have occurred in children aged under 5 years, which is equivalent to $70 \%$ of the global total. Malaria remains a major killer of children, taking the life of a child every $2 \mathrm{~min}$. The spread of anti-malarial drug resistance from Southeast Asia to Africa has previously occurred with chloroquine and sulfadoxine-pyrimethamine $[2,3]$. The emergence of resistance to artemisinins, manifested by delayed parasite clearance after monotherapy with artesunate or ACT, was described in Southeast Asia $[4,5]$. Drug resistance is currently emerging even to the most recently commercialized ACT, dihydroartemisinin-piperaquine, in Cambodia, where $84 \%$ of treated patients showed delayed parasite clearance halflives in 2012-2014 [6-8]. Antibiotics, and more specifically doxycycline, have been shown to be effective against malaria parasites [9-11]. Doxycycline is recommended for malaria chemoprophylaxis for travel in endemic areas $[12,13]$. Considering doxycycline delayed onset of action, this finding justifies its therapeutic use in combination 
with a fast schizonticide [11]. The addition of doxycycline for severe malaria was much more as an attempt to reduce the emergence of resistance, and reduce the use of artesunate or quinine monotherapy. Doxycycline can alter recrudescent parasites. Additionally, doxycycline can also prevent bacterial infections which could be associated with malaria. Doxycycline is recommended in combination with quinine for malaria treatment in the event of ACT unavailability in some European clinical practice $[14,15]$. This combination is also used when treatment of severe malaria with artesunate fails [16]. In some African hospitals, oral doxycycline is used systematically in combination with intravenous artesunate in the treatment of severe P. falciparum malaria [17]. Additionally, some severe $P$. vivax cerebral malaria cases have been treated with artesunate and doxycycline [18, 19]. However, doxycycline is contraindicated in children under 8 years of age because of the risk of yellow tooth discolouration and dental enamel hypoplasia.

In this review, the potential effects of doxycycline on teeth were re-analysed. Information sources were identified using PubMed, Google Scholar and Google. Searches were performed in these electronic databases using the search term 'doxycycline' alone or in combination with 'teeth' or 'children' or 'side-effects'.

\section{Potential for adverse dental effects}

Tetracycline compounds have been used since 1953 . Doxycycline was developed in 1967. Unfortunately, doxycycline was labelled with the same side-effects as had been reported for the tetracyclines, including the risk of yellow tooth discolouration and dental enamel hypoplasia in children under 8 years of age.

In the early 1960 s, dental side-effects were associated with the use of tetracycline. Children suffering with cystic fibrosis who were treated with tetracycline (41-63 children) presented a high prevalence (38$80 \%)$ of discoloured teeth after long-term treatment [20-22]. The incidence of permanent staining of teeth was greater with high doses of tetracycline and longterm administration, but tetracycline also pigmented the teeth of $23-92 \%$ of babies or children after short courses of treatment (55/238, 16/23 and 46/50 babies) or led to hypoplasia of the enamel [23-25]. In a large study in 520 children, tetracycline was determined to be the probable causative agent of dental defects in 112 cases $(21.5 \%)$ [26]. Due to these results, all the tetracyclines were contraindicated in children under 8 years of age because of the risk of yellow tooth discolouration and dental enamel hypoplasia. However, it was shown in experimental animals that tooth discolouration was more associated with tetracycline than with chlortetracycline or oxytetracycline [27]. Doxycycline has a lower affinity to chelate calcium (19\%) compared to tetracycline (39.5-74.5\%), leading to a reduced risk of yellow tooth discolouration and dental enamel hypoplasia [2831]. Studies using doxycycline in children have reported little or no effect on teeth. Lochary and co-workers did not find any significant difference in dental staining between 10 children treated with doxycycline and 20 control children without treatment [32]. A randomized, blind, controlled study in young children with refractive atypical pneumonia did not detect tooth staining in either group (31 children with doxycycline and 30 control non-doxycycline exposed children) [33]. Most of the children were under 4 years of age when they were treated with doxycycline. Doxycycline was administered in syrup form at a dose of $4 \mathrm{mg} / \mathrm{kg}$ twice a day on the first day followed by a single dose of $2 \mathrm{mg} / \mathrm{kg}$ for nine days. Some children received up to four courses of doxycycline before the age of 8 years (mean of 2.0 courses per child). In another study, 58 children who lived in an American-Indian reservation were treated with doxycycline for suspected Rocky Mountain spotted fever (RMSF) with a mean duration of 7.3 days before the age of eight [34]. These children received multiple courses of doxycycline, with a mean of 1.8 courses per child and a total of 107 courses for the group. There was no difference in yellow tooth discolouration and dental enamel hypoplasia between children who were treated with doxycycline and 213 non-exposed children.

\section{Discussion}

These different studies showed that short courses of doxycycline in children under 8 years of age had no visible dental effects, such as staining of teeth or enamel hypoplasia. Recently, discolouration of teeth was observed (2.8\%) in adults receiving prolonged courses of doxycycline (100 mg twice a day for 6 months) for abdominal aortic aneurysms [35].

Doxycycline is a cheap drug with a broad therapeutic spectrum and very little evidence of serious adverse events [36]. It is time to recommend the use of doxycycline in children under 8 years of age for short course treatments [37-40]. Since 2013, the Centers for Disease Control and Prevention (CDC) have recommended the use of doxycycline at a dose of $2.2 \mathrm{mg} / \mathrm{kg}$ twice per day for two weeks in children under 8 years of age for the treatment of acute and chronic Q fever in United States [41]. The CDC Rickettsial Zoonoses Branch recommended the use of doxycycline for treatment of tick-borne rickettsial diseases in the United States in 2016 [42]. It is time now to use doxycycline in young children for malaria treatment in combination with artesunate or quinine, in line with its recommended use for adults and children older than 8 years of age [14-16]. For chemoprophylaxis for 
young children travellers (long-term course), the recommendations should remain unchanged $[12,13]$.

Additionally, intermittent preventive treatment in infants (IPTi) is recommended by the WHO [43]. Intermittent preventive treatment in children (IPTc), especially in schoolchildren (IPTsc), is a proven malaria control strategy [44-46]. In Africa, school-aged children represent $26 \%$ of the population, and nearly half of these children have at least one malaria infection each year [47]. In evaluating different schedules, children were treated every 5 months, 4 months, 3 months, 2 months or every month with sulfadoxine-pyrimethamine, sulfadoxine-pyrimethamine-amodiaquine, sulfadoxinepyrimethamine-artesunate, amodiaquine-artesunate, or dihydroartemisinin-piperaquine [46, 48-52]. Doxycycline, which is a low-half-life drug $(20 \mathrm{~h})$ [11], could be associated with long-half-life drugs such as amodiaquine, piperaquine or sulfadoxine-pyrimethamine in young children for IPTsc. An advantage of using doxycycline is its mechanism of action which differs from those of most currently used anti-malarial drugs by inhibiting proteins implicated in apicoplast metabolism [11, 53, 54].

However, the use of doxycycline for malaria chemoprophylaxis could raise the risk of selecting resistant bacterial pathogens to antibiotics [55]. The microbiome plays an important role in human health, and changes in the microbial flora can lead to resistance or infection by pathogenic bacteria. Proliferation of pathogenic bacteria in the human microbiome has been documented following antibiotic exposure [56, 57]. Q fever endocarditis patients treated with doxycycline presented significantly lower concentrations of Bacteroidetes, Firmicutes and Lactobacillus [58], a finding that was also observed with the anti-malarial hydroxychloroquine [58]. Anti-malarial drugs certainly have an impact on the microbiota. It is important to determine the effects of doxycycline on the microbiome, especially if multiple antibacterial combinations are used like sulfadoxine-pyrimethamine and doxycycline, especially in young children. The impact of long-term chemoprophylaxis with doxycycline on bacterial pathogens is documented only in military clinical cases with the acquisition of multi-drug resistance by bacteria [59-62]. However, these increases in multi-drug-resistant bacteria were likely associated with environmental exposures rather than doxycycline exposure. Only outbreaks of PantonValentine leukocidin-positive, doxycycline-resistant, methicillin-susceptible Staphylococcus aureus infections have been linked to long-term chemoprophylaxis with doxycycline in soldiers under deployment [63]. There is no published information on the development of bacterial resistance after short-courses of doxycycline used in malaria prophylaxis.

\section{Conclusions}

Doxycycline was developed after tetracycline and was labelled with the same side-effects as the earlier tetracyclines, including the risk of yellow tooth discolouration and dental enamel hypoplasia in children under 8 years of age. However, recent studies report little or no effects of doxycycline on tooth staining or dental enamel hypoplasia in children under 8 years of age. In the United States, the CDC have recommended the use of doxycycline for the treatment of acute and chronic $\mathrm{Q}$ fever and tick-borne rickettsial diseases in young children. It is time to rehabilitate doxycycline and to recommend it in combination with the use of quinine for malaria treatment when ACT is unavailable or when the treatment of severe malaria with artesunate fails, in children under 8 years of age. Doxycycline could also be associated with long-half-life drugs such as amodiaquine, piperaquine or sulfadoxine-pyrimethamine in young children for IPTsc.

\section{Abbreviations}

ACT: artemisinin-based combination therapy; CDC: Centers for Disease Control and Prevention; IPTc: intermittent preventive treatment for children; IPTi: intermittent preventive treatment for infants; IPTsc: intermittent preventive treatment for schoolchildren; WHO: World Health Organization.

\section{Authors' contributions}

All authors read and approved the final manuscript.

\section{Author details}

${ }^{1}$ Fédération des Laboratoires, Hôpital d'Instruction des Armées Desgenettes, Lyon, France. ${ }^{2}$ Unité de Parasitologie et d'Entomologie, Département des Maladies Infectieuses, Institut de Recherche Biomédicale des Armées, HIA Laveran, Boulevard Laveran, 13013 Marseille, France. ${ }^{3}$ Aix Marseille Université, Unité de Recherche sur les Maladies Infectieuses et Tropicales Emergentes, UM 63, CNRS 7278, IRD 198, Inserm 1095, Institut Hospitalo-universitaire Méditerranée Infection, Marseille, France. ${ }^{4}$ Centre National de Référence du Paludisme, Marseille, France.

\section{Acknowledgements}

Not applicable.

Competing interests

The authors declare that they have no competing interests.

\section{Publisher's Note}

Springer Nature remains neutral with regard to jurisdictional claims in published maps and institutional affiliations.

Received: 21 November 2016 Accepted: 4 April 2017

Published online: 13 April 2017

\section{References}

1. WHO. World Malaria Report 2016. Geneva: World Health Organization; 2016.

2. Mita T, Venkatesan M, Ohashi J, Culleton R, Takahashi N, Tsukahara T, et al. Limited geographical origin and global spread of sulfadoxineresistant dhps alleles in Plasmodium falciparum populations. J Infect Dis. 2011;204:1980-8.

3. Wootton JC, Feng X, Ferdig MT, Cooper RA, Mu J, Baruch DI, et al. Genetic diversity and chloroquine selective sweeps in Plasmodium falciparum. Nature. 2002;418:320-3. 
4. Dondorp AM, Nosten F, Yi P, Das D, Phyo AP, Tarning J, et al. Artemisinin resistance in Plasmodium falciparum malaria. N Engl J Med. 2009;361:455-67.

5. Ashley EA, Dhorda M, Fairhurst RM, Amaratunga C, Lim P, Suon S, et al. Spread of artemisinin resistance in Plasmodium falciparum malaria. N Engl J Med. 2015;371:411-23.

6. Leang R, Taylor WR, Bouth DM, Song L, Tarning J, Char MC, et al. Evidence of Plasmodium falciparum malaria multidrug resistance to artemisinin and piperaquine in Western Cambodia: Dihydroartemisinin-Piperaquine open-label multicenter clinical assessment. Antimicrob Agents Chemother. 2015:59:4719-26.

7. Spring MD, Lin JT, Manning JE, Vanachayangkul P, Somethy S, Bun R, et al. Dihydroartemisinin-piperaquine failure associated with a triple mutant including kelch13 C580Y in Cambodia: an observational cohort study. Lancet Infect Dis. 2015;15:683-91.

8. Amaratunga C, Lim P, Suon S, Sreng S, Mao S, Sopha C, et al. Dihydroartemisinin-piperaquine resistance in Plasmodium falciparum malaria in Cambodia: a multisite prospective cohort study. Lancet Infect Dis. 2016;16:357-65.

9. Gaillard T, Dormoi J, Madamet M, Pradines B. Macrolides and associated antibiotics based on similar mechanism of action like lincosamides in malaria. Malar J. 2016:15:85.

10. Gaillard T, Madamet M, Foguim Tsombeng F, Dormoi J, Pradines B. Antibiotics in malaria therapy: which antibiotics except tetracyclines and macrolides may be used against malaria? Malar J. 2016;15:556.

11. Gaillard T, Madamet M, Pradines B. Tetracyclines in malaria. Malar J. 2015;14:445.

12. CDC. Health information for international travel. Yellow book 2016. Atlanta: Centers for Diseases Control and Prevention; 2016.

13. Haut Conseil de la Santé Publique. Recommandations sanitaires pour les voyageurs 2016. Bulletin Epidémiologique Hebdomadaire, hors série, 2016

14. Société de Pathologie Infectieuse de Langue Française. Recommendations for clinical practice Management and prevention of imported Plasmodium falciparum malaria (Revision 2007 of the 1999 Consensus conference). Med Mal Infect. 2008;38:54-67.

15. Lalloo DG, Shingadia D, Bell DJ, Beeching NJ, Whitty CJ, Chiodini PL. PHE Advisory Committee on Malaria Prevention in UKTravellers. UK malaria treatment guidelines 2016. J Infect. 2016;2:635-49.

16. Van Hong N, Amambua-Ngwa A, Tuan NQ, Cuong do D, Giang NT, Van Dung $N$, et al. Severe malaria not responsive to artemisinin derivatives in man returning from Angola to Vietnam. Emerg Infect Dis. 2014;20:1199-202.

17. Diawara S, Madamet M, Kounta MB, Lo G, Wade KA, Nakoulima A, et al. Confirmation of Plasmodium falciparum in vitro resistance to monodesethylamodiaquine and chloroquine in Dakar, Senegal, in 2015. Malar J. 2017;16:118.

18. Gupta H, Dhunputh P, Bhatt AN, Satyamoorthy K, Umakanth S. Cerebral malaria in a man with Plasmodium vivax mono-infection: a case report. Trop Doct. 2016:46:241-5

19. Amireh S, Shaaban H, Guron G. Severe Plasmodium vivax cerebral malaria complicated by hemophagocytic lymphohistiocytosis treated with artesunate and doxycycline. Hematol Oncol Stem Cell Ther. 2016;3876(16):30035-8.

20. Shwachman H, Fekete E, Kulczycki LL, Foley GE. The effect of long-term antibiotic therapy in patients with cystic fibrosis of the pancreas. Antibiot Annu. 1958:6:692-9.

21. Swallow JN, De Haller J, Young WF. Side-effects to antibiotics in cystic fibrosis: dental changes in relation to antibiotic administration. Arch Dis Child. 1967:42:311-8.

22. Zegarelli EV, Denning CR, Kutscher AH, Fahn B, Kirschner G, Slaughter TW. Discoloration of teeth in patients with cystic fibrosis of the pancreas: role of tetracycline therapy. Clin Pediatr (Phila). 1963;2:329-31.

23. Wallman IS, Hilton HB. Teeth pigmented by tetracycline. Lancet. 1962;1:827-9.

24. Conchie JM, Munroe JD, Anderson DO. The incidence of staining of permanent teeth by the tetracyclines. Can Med Assoc J. 1970;103:351-6.

25. Kowalewska B, Szotowa W, Winiarska-Majczyno M. Tetracyclines and the teeth. Lancet. 1966;2:387.

26. Rebich T, Kumar J, Brustman B. The St. Regis environmental health issue: assessment of dental defects. J Am Dental Assoc. 1983;106:630-3.
27. Ibsen $\mathrm{KH}$, Urist MR, Sognnaes RF. Differences among tetracyclines with respect to the staining of teeth. J Pediatr. 1965;67:459-62.

28. Forti G, Beniucori C. Doxycycline and the teeth. Lancet. 1969;1:782.

29. Tredwin CJ, Scully C, Bagan-Sebastian JV. Drug-induced disorders of teeth. J Dent Res. 2005:84:596-602.

30. Caswell AH, Hutchison JD. Selectivity of cation chelation to tetracyclines: evidence for special conformation of calcium chelate. Biochem Biophys Res Commun. 1971;43:625-30.

31. Lambrou DB, Tahos BS, Lambrou KD. In vitro studies of the phenomenon of tetracycline incorporation into enamel. J Dent Res. 1977;56:1527-32.

32. Lochary ME, Lockhart PB, Williams WT. Doxycycline and staining of permanent teeth. Pediatr Infect Dis J. 1998;17:429-31.

33. Volovitz B, Shkap R, Amir J, Calderon S, Varsano I, Nussinovitch M. Absence of tooth staining with doxycycline treatment in young children. Clin Pediatr. 2007:46:121-6.

34. Todd SR, Dahlgren S, Traeger MS, Beltran-Aguilar ED, Marianos DW, Hamilton $C$, et al. No visible dental staining in children treated with doxycycline for suspected Rocky Mountain spotted fever. J Pediatr. 2015;166:1246-51.

35. Baxter BT, Pearce WH, Waltke EA, et al. Prolonged administration of doxycycline in patients with small asymptomatic abdominal aortic aneurysms: report of a prospective (Phase II) multicenter study. J Vasc Surg. 2002;36:1-12.

36. Smith K, Leyden JJ. Safety od doxycycline and minocycline: a systematic review. Clin Ther. 2005;27:1329-42.

37. Cross R, Ling C, Day NP, McGready R, Paris DH. Revisiting doxycycline in pregnancy and early childhood-time to rebuild its reputation? Expert Opin Drug Saf. 2016;15:367-82.

38. Long SS. Good news about doxycycline and dental staining. J Pediatr 2015;166:1101-4

39. Cale DF, McCarthy MW. Treatment of Rocky Mountain spotted fever in children. Ann Pharmacother. 1997:31:492-4.

40. Anonymes. Addentum: Doxycycline for young children. Med Lett Drug Ther. 2016:58:82.

41. CDC. Diagnosis and management of $Q$ fever-United States. Recommendations from CDC and the Q fever working group. MMWR Recomm Rep. 2013;2013(62):1-29.

42. Biggs HM, Behravesh CB, Bradley KK, Dahlgren FS, Drexler NA, Dumler JS, et al. Diagnosis and Management of Tickborne Rickettsial Diseases: Rocky Mountain Spotted Fever and Other Spotted Fever Group Rickettsioses, Ehrlichioses, and Anaplasmosis - United States. MMWR Recomm Rep. 2016:65:1-44.

43. WHO. Guidelines for the treatment of malaria. 3rd edition. Geneva: World Health Organization; 2015.

44. Meremikwu MM, Donegan S, Sinclair D, Esu E, Oringanje C. Intermittent preventive treatment for malaria in children living in areas with seasonal transmission. Cochrane Database System Rev. 2012;15:CD003756.

45. Matangila JR, Mitashi P, Inocêncio da Luz RA, Lutumba PT, Van Geertruyden JP. Efficacy and safety of intermittent preventive treatment for malaria in schoolchildren: a systematic review. Malar J. 2015;14:450

46. Nankabirwa JI, Wandera B, Amuge P, Kiwanuka N, Dorsey G, Rosenthal $P J$, et al. Impact of intermittent preventive treatment with dihydroartemisinin-piperaquine on malaria in Ugandan schoolchildren: a randomized, placebo-controlled trial. Clin Infect Dis. 2014;58:1404-12.

47. Clarke SE, Brooker S, Njagi JK, Njau E, Estambale B, Muchiri E, et al. Malaria morbidity among school children living in two areas of contrasting transmission in western Kenya. Am J Trop Med Hyg. 2004:71:732-8.

48. Clarke SE, Jukes MC, Njagi JK, Khasakhala L, Cundill B, Otido J, et al. Effect of intermittent preventive treatment of malaria on health and education in schoolchildren: a cluster-randomised, double-blind, placebo-controlled trial. Lancet. 2008;372:127-38.

49. Dicko A, Sagara I, Sissoko MS, Guindo O, Diallo Al, Kone M, et al. Impact of intermittent preventive treatment with sulphadoxine-pyrimethamine targeting the transmission season on the incidence of clinical malaria in children in Mali. Malar J. 2008;7:123.

50. Barger B, Maiga $\mathrm{H}$, Traore OB, Tekete M, Tembine I, Dara A, et al. Intermittent preventive treatment using artemisinin-based combination therapy reduces malaria morbidity among school-aged children in Mali. Trop Med Int Health. 2009;14:784-91.

51. Nankabirwa J, Cundill B, Clarke S, Kabatereine N, Rosenthal PJ, Dorsey G, et al. Efficacy, safety, and tolerability of three regimens for prevention of malaria: a randomized, placebo-controlled trial in Ugandan schoolchildren. PLoS ONE. 2010;5:e13438. 
52. Tine RC, Faye B, Ndour CT, Ndiaye JL, Ndiaye M, Bassene C, et al. Impact of combining intermittent preventive treatment with home management of malaria in children less than 10 years in a rural area of Senegal: a cluster randomized trial. Malar J. 2011;10:358.

53. Dahl EL, Shock JL, Shenai BR, Gut J, DeRisi JL, Rosenthal PJ. Tetracyclines specifically target the apicoplast of the malaria parasite Plasmodium falciparum. Antimicrob Agents Chemother. 2006;50:3124-31.

54. Briolant S, Almeras L, Belghazi M, Boucomont-Chapeaublanc E, Wurtz N, Fontaine $\mathrm{JC}$, et al. Plasmodium falciparum proteome changes in response to doxycycline treatment. Malar J. 2010;9:141.

55. Chopra I, Roberts M. Tetracycline antibiotics: mode of action, applications, molecular biology, and epidemiology of bacterial resistance. Microbiol Mol Biol Rev. 2001;65:232-60.

56. Angelakis E, Merhej $\mathrm{V}$, Raoult D. Related actions of probiotics and antibiotics on gut microbiota and weight modification. Lancet Infect Dis. 2013;13:889-99

57. Bäumler AJ, Sperandio V. Interactions between the microbiota and pathogenic bacteria in the gut. Nature. 2016;535:85-93.

58. Angelakis E, Million M, Kankoe S, Lagier JC, Armougom F, Giorgi R, et al. Abnormal weight gain and gut microbiota modifications are side effects of long-term doxycycline and hydroxychloroquine treatment. Antimicrob Agents Chemother. 2014:58:3342-7.

59. Taylor DN, Pitarangsi C, Echeverria P, Diniega BM. Campylobacter enteritis during doxycycline prophylaxis for malaria in Thailand. Lancet. 1988;2:578-9.

60. Arthur JD, Echeverria P, Shanks GD, Karwacki J, Bodhidatta L, Brown JE. A comparative study of gastrointestinal infections in United States soldiers receiving doxycycline or mefloquine for malaria prophylaxis. Am J Trop Med Hyg. 1990:43:608-13.

61. Vento TJ, Cole DW, Mende K, Calvano TP, Rini EA, Tully C, et al. Multidrugresistant gram-negative bacteria colonization of healthy US military personnel in the US and Afghanistan. BMC Infect Dis. 2013;13:68.

62. Vento TJ, Cole DW, Mende K, Calvano TP, Rini EA, Tully C, et al. Staphylococcus aureus colonization of healthy military service members in the United States and Afghanistan. BMC Infect Dis. 2013;13:325.

63. Lesens O, Haus-Cheymol R, Dubrous P, Verret C, Spiegel A, Bonnet R, et al. Methicillin-susceptible, doxycycline-resistant Staphylococcus aureus, Côte d'Ivoire. Emerg Infect Dis. 2007:13:488-90.

\section{Submit your next manuscript to BioMed Central and we will help you at every step:}

- We accept pre-submission inquiries

- Our selector tool helps you to find the most relevant journal

- We provide round the clock customer support

- Convenient online submission

- Thorough peer review

- Inclusion in PubMed and all major indexing services

- Maximum visibility for your research

Submit your manuscript at www.biomedcentral com/submit 